\title{
Implementasi Algoritma RSA Pada Sistem Pendukung Keputusan Pengalokasian Dana Bantuan Langsung Masyarakat Dengan Metode Weighted Product (Studi Kasus Desa Beka Kecamatan Marawola Kabupaten Sigi)
}

\author{
Deny Wiria Nugraha1), A.Y. Erwin Dodu'2), Abdul Rahim ${ }^{3)}$ \\ Jurusan Teknologi Informasi Fakultas Teknik Universitas Tadulako. \\ deny.wiria.nugraha@gmail.com¹), ayerwin.dodu@gmail.com²), rahimhmti84@gmail.com³)
}

\begin{abstract}
Abstrak
Bantuan langsung masyarakat merupakan program pemerintah untuk mengurangi tingkat kemiskinan masyarakat indonesia, dengan menyediakan dana kepada masyarakat miskin. Namun, sering kali bantuan yang diberikan oleh pemerintah tersebut tidak tepat sasaran dimana bantuan yang seharusnya dikhususkan untuk masyarakat yang kurang mampu, tetapi masyarakat yang mampu dalam hal materi pun malah mendapatkan dana tersebut selain itu proses pelaksanaan bantuan masih bersifat manual sehingga membutuhkan waktu yang cukup lama dan tujuan pemerintah dalam mengurangi tingkat kemiskinan tidak terlaksana dengan baik. Berdasarkan studi literatur yang dilakukan didapatkan bahwa sistem pendukung keputusan dapat mengatasi permasalah pemberian bantuan langsung masyarakat dan metode yang digunakan adalah metode Weighted Product karena dapat bekerja lebih efektif dan efesien dibanding metode yang lain. Hasil penelitian ini menunjukkan bahwa sistem pendukung keputusan dapat mengatasi masalah penerima bantuan langsung masyarakat yang masih dilakukan secara manual dan subyektif di Desa Beka Kecamatan Marawola Kabupaten Sigi sehingga proses penyaluran bisa lebih cepat dan proposisi dan algoritma RSA yang digunakan mampu memberikan keamanan data kuat.
\end{abstract}

Kata kunci : Kriptografi, Rivest Shamir dan Adleman (RSA), Sistem Pendukung Keputusan (SPK), Weighted Product (WP).

\begin{abstract}
Immediate relief society is the Government's programme to reduce the poverty levels of society, by providing funds to the poor. However, often the assistance provided by the Government are not right on target in which the assistance should be devoted to the underprivileged community, but the community that are capable of in terms of material ever even get those funds in addition the process of implementation of assistance are still manual so need quite a long time and the purpose of the Government in reducing the level of poverty is not done properly. Based on the study of the literature undertaken obtained a decision support system that can address the problem of granting direct aid community and the method used is weighted product method because it can work more affectively and efficiently than any other method. The results of this study indicate that a decision support system can address the issue of the direct recipient of the community that is still done manually and subjective in village Beka Sub Marawola tropospheric processes so Sigi Regency can faster and the $R S A$ algorithm and propositions that are used to provide strong data security.
\end{abstract}

Keywords : Cryptography, Rivest Shamir Adleman and (RSA), A Decision Support System(SPK), Weighted Product (WP).

\section{PENDAHULUAN}

Bantuan langsung masyarakat merupakan program pemerintah yang menyediakan dana kepada masyarakat miskin, susuai dengan Peraturan Pemerintah Nomor 63 Tahun 2013 Tentang Pelaksanaan Upaya Penanggulangan Fakir Miskin Melalui Pendekan Wilayah. Menurut masyarakat desa beka yaitu Samsir dan Sutarjo, sering kali bantuan yang diberikan oleh pemerintah tersebut tidak tepat sasaran dimana bantuan yang seharusnya dikhususkan untuk masyarakat yang kurang 
mampu, tetapi masyarakat yang mampu dalam hal materi pun malah mendapatkan dana tersebut. Hal ini menyebabkan masih banyak dana bantuan tersebut yang tidak tepat sasaran kepada masyarakat. Salah satu daerah yang masih perlu diperhatikan berkaitan permasalahan ini adalah daerah Kecamatan Marawola, Kabupaten Sigi, khususnya di Desa Beka. Di desa tersebut proses penyeleksian masyarakat yang kurang mampu masih menggunakan perhitungan manual yaitu dengan merata-ratakan beberapa kriteria yaitu berapa penghasilan dari satu kepala keluarga, dilihat layak huninya suatu hunian dan masih banyak lagi. Di desa Beka jumlah masyarakat mencapai 2649 jiwa dengan jumlah $609 \mathrm{KK}$. Sehingga pemerintah lebih lambat menyeleksi masyarakat yang lebih layak untuk mendapatkan bantuan tersebut. Dan keamanan data merupakan hal yang penting bagi pemerintahan dimana jika data tersebut disalahgunakan dapat merugikan pemerintah dalam upaya penanggulangan kemiskinan berupa dampak pengangambil alihan data dan memanipulasi data dan untuk memastikan keamanan data yang tersimpan pada database agar tidak dapat diakses oleh pihak lain, maka dibutuhkan suatu keamanan yang kuat pada sistem.

Berdasarkan studi literatur dapat disimpulkan bahwa untuk mengatasi masalah penerima bantuan langsung masyarakat yang masih bersifat manual dan subyektif dapat dilakukan dengan membangun sistem pendukung keputusan dan untuk mendapatkan hasil keputusan sistem yang lebih cepat,efektif dan efesien dengan menggunakan metode Weighted Product (WP) yang dapat bekerja lebih efektif dan efesien dibanding metode yang lain, dengan rata-rata waktu yang lebih cepat. Untuk keaman data dalam database algoritma RSA lebih aman dan lebih cepat dalam mengamankan data, oleh karena itu penulis mengimplementasikan algoritma RSA untuk mengamankan data dalam database sistem pendukung keputusan bantuan langsung masyarakat dengan metode Weighted Product (WP).

Berdasarkan permasalahan yang telah diuraikan di atas maka penulis membuat penelitian dengan judul "Implementasi Algoritma RSA Pada Sistem Pendukung Keputusan Pengalokasian Dana Bantuan Langsung Masyarakat Dengan Metode Weighted Product (Studi Kasus Desa Beka, Kecamatan Marawola, Kabupaten Sigi)".

\subsection{Rumusan Masalah}

Berdasarkan latar belakang di atas maka rumusan masalah dalam penelitian ini adalah sebagai berikut :

1. Bagaimana mengimplementasikan algoritma RSA pada sistem pendukung keputusan pengalokasian dana bantuan langsung masyarakat dengan metode weighted product pada aplikasi berbasis web?

2. Bagaimana menguji solusi ?

\subsection{Batasan Masalah}

Batasan masalah dalam penelitian ini adalah sebagai berikut :

1. Sistem ini akan mengenkripsikan data record database hasil keputusan sistem.

2. Kriteria yang digunakan dalam sistem tidak dapat ditambahkan.

3. Terdapat satu kunci private dan satu kunci public

4. Tidak dapat merubah dan menambahkan kunci Private dan Public

\subsection{Tujuan Penelitian}

Adapun tujuan dari penelitian ini adalah mengimplementasikan sistem pendukung keputusan pengalokasian dana bantuan langsung masyarakat menggunakan metode weighted product berbasis web untuk membantu pemerintah dalam menyeleksi masyarakat yang lebih layak mendapatkan dana bantuan dan Mengunci data hasil keputusan sistem menggunakan algoritma RSA.

\section{TEORI DASAR}

\section{A. Sistem Pendukung Keputusan}

Sistem pendukung keputusan adalah sebuah sistem yang memilih tindakan di antara berbagai alternatif untuk mencapai sebuah atau beberapa tujuan. Salah satu hal penting dalam proses pendukung keputusan adalah proses pengumpulan informasi yang mana terkait dengan situasi keputusan yang ada. Untuk membuat optimal sistem pendukung keputusan ini, sebuah sistem berbasis komputer perlu dikembangkan secara interaktif untuk memecahkan masalah yang tidak terstruktur dengan memanfaatkan data maupun model yang ada. Sistem pendukung keputusan dapat 
dikatakan berhasil apabila sistem tersebut memiliki kriteria antara lain sederhana, cepat, mudah dikontrol, adaptif, memiliki informasi lengkap, dan mudah untuk dilakukan komunikasi.[9]

Konsep Sistem Pendukung Keputusan (SPK) atau Decision Support Systems (DSS) pertama kali diungkapkan pada awal tahun 1970-an oleh Michael S. Scott Morton dengan istilah Management Decision Systems. SPK adalah bagian dari sistem informasi berbasis komputer yang dipakai untuk pendukung keputusan dalam suatu organisasi atau perusahaan. Dapat juga dikatakan sebagai sistem komputer yang mengolah data menjadi informasi untuk mengambil keputusan dari masalah semiterstruktur yang spesifik. Tujuan dari SPK adalah membantu menyelesaikan masalah semiterstruktur, mendukung manajer dalam pendukung keputusan serta meningkatkan efektifitas bukan efisiensi pendukung keputusan. SPK bukanlah suatu tool pengambil keputusan, melainkan sebagai tool pendukung.[9]

\section{B. Weighted Product (WP)}

merupakan metode yang menyelesaikan masalah Multi Attribute Decision Making (MADM). Metode Weighted Product (WP) adalah suatu metode yang menggunakan perkalian untuk menghubungkan nilai atribut (kriteria), dimana nilai setiap atribut (kriteria) harus dipangkatkan dulu dengan bobot atribut (kriteria) yang bersangkutan [11].

Langkah-langkah yang dilakukan dalam penyelesaian masalah menggunakan metode Weighted Product adalah [11]:

1. Normalisasi atau Perbaikan Bobot

Persamaan untuk normalisasi atau perbaikan

bobot dapat dilihat pada persamaan (1).

$$
w_{j}=\frac{\mathrm{w}}{\sum w_{j}}
$$

Keterangan:

Persamaan ini akan melakukan normalisasi atau perbaikan bobot untuk menghasilkan nilai $w_{j}=1$ dimana $1,2, \ldots ., \mathrm{n}$ adalah banyak alternatif dan $\Sigma w_{j}$ adalah jumlah keseluruhan nilai bobot. Variabel $\mathrm{W}$ adalah nilai indeks ke j yang bernilai positif untuk atribut keuntungan dan bernilai negatif untuk atribut biaya.

2. Menentukan Nilai Vektor (S)

Persamaan untuk menentukan nilai vektor (s) dapat dilihat pada persamaan (2).

$$
S_{i}=\prod_{J=1}^{n} \mathrm{X}_{i_{j}}{ }^{w_{j}}
$$

$\Pi$ : product

$\mathrm{Si} \quad$ : skor / nilai dari setiap alternatif

$X i_{j}$ :nilai alternatif ke-i terhadap atribut $\mathrm{j}$

$w_{j}$ : bobot dari setiap atribut atau kriteria

$\mathrm{n}$ : Banyaknya kriteria

3. Menentukan Nilai Vektor (V)

Persamaan untuk menentukan nilai vektor (v) yang dapat dilihat pada persamaan (3)

$$
V i=\frac{\mathrm{Si}}{\prod_{J=1}^{n}\left(X_{J}^{*}\right) w_{j}}
$$

Keterangan:

$\mathrm{V}$ : Preferensi alternatif dianalogikan sebagai vektor $\mathrm{V}$

$X$ : NilaiKriteria.

W : Bobot kriteria/subkriteria

I : Alternatif

$\mathrm{J}$ : Kriteria

$\mathrm{n}$ : Banyaknya kriteria

* : Banyaknya kriteria yang telah dinilai pada vektor S.

Adapun kelebihan dan kekurangan dari metode weighted product ini adalah sebagai berikut : 


\section{Kelebihan Metode WP}

a. Mempercepat proses perhitungan nilai kriteria dan perangkingan untuk setiap alternatif.

b. Mempermudah user untuk memberikan pembobotan terhadap kriteria yang memiliki nilai yang hampir sama.

c. Dapat digunakan untuk pengambilan keputusan single dan keputusan multidimensional.

d. Metode ini digunakan untuk menyelesaikan pengambilan keputusan secara praktis, karena konsepnya sederhana dan mudah dipahami.

2. Kekurangan Metode WP

a. Tidak banyak user yang menggunakan metode ini dalam pengambilan keputusan.

b. Metode ini hanya metode matematis tanpa ada pengujian secara statistik sehingga tidak ada batas kepercayaan dari kebenaran model yang terbentuk.

\section{Kriptografi}

Kriptografi adalah ilmu dan seni untuk menjaga kerahasiaan pesan dengan cara menyandikannya ke dalam bentuk yang tidak dapat dimengerti lagi maknanya. Dalam ilmu kriptografi, terdapat dua buah proses yaitu melakukan enkripsi dan dekripsi. Pesan yang akan dienkripsi disebut sebagai plaintext (teks biasa). Disebut demikian karena informasi ini dengan mudah dapat dibaca dan dipahami oleh siapa saja. Algoritma yang dipakai untuk mengenkripsi dan mendekripsi sebuah plaintext melibatkan penggunaan suatu bentuk kunci. Pesan plaintext yang telah dienkripsi (atau dikodekan) dikenal sebagai ciphertext (teks sandi). Di dalam kriptografi kita akan sering menemukan berbagai istilah atau terminology [6].

Beberapa istilah yang harus diketahui yaitu :

1. Pesan, Plainteks, dan Cipherteks

Pesan (message) adalah data atau informasi yang dapat dibaca dan dimengerti maknanya. Nama lain untuk pesan adalah (plaintext) atau teks jelas (cleartext).

2. Pengirim dan Penerima Komunikasi

Data melibatkan pertukaran pesan antara dua entitas. Pengirim (sender) adalah entitas yang mengirim pesan kepada entitas lainnya. Penerima (receiver) adalah entitas yang menerima pesan.

3. Enkripsi dan dekripsi

Proses menyandikan plainteks menjadi cipherteks disebut enkripsi (encryption) atau enciphering. Sedangkan proses mengembalikan cipherteks menjadi plainteks semula disebut dekripsi (decryption).

4. Cipher dan kunci

Algoritma kriptografi disebut juga cipher, yaitu aturan untuk enkripsi dan dekripsi, atau fungsi matematika yang digunakan untuk enkripsi dan dekripsi.

\section{Tujuan Kriptografi}

Tujuan kriptografi untuk memberi layanan keamanan. Yang dinamakan aspek-aspek keamanan antara lain :

1. Kerahasiaan (confidentiality) Adalah layanan yang ditujukan untuk menjaga agar pesan tidak dapat dibaca oleh pihak-pihak yang tidak berhak.

2. Integritas data (data integrity) Adalah layanan yang menjamin bahwa pesan masih asli atau belum pernah dimanipulasi selama pengiriman.

3. Otentikasi (authentication) Adalah layanan yang berhubungan dengan identifikasi, baik mengidentifikasi kebenaran pihak pihak yang berkomunikasi (user autehentication).

4. Non-repudiation Adalah layanan untuk menjaga entitas yang berkomunikasi melakukan penyangkalan [6].

\section{E. Algoritma RSA}

Sistem kriptografi RSA adalah salah satu sistem kriptografi kunci publik yang ditemukan oleh Rivest, Shamir dan Adleman dari Massachusset Institute of Technology (MIT) pada tahun 1976. Sejak skema sistem ini ditemukan, sistem ini menguasai sebagai satu-satunya sistem yang diterima 
dan diterapkan secara luas sebagal sistem kriptografi kunci publik. Sistem ini termasuk sistem enkripsi blok, karena data asli dan data sandi adalah bilangan integer antara 0 sampai $(n-1)$, untuk semua nilal $n$ positif. Keamanan sistem kriptografi ini bergantung kondisi tertentu. Seperti kebanyakan sistem kriptografi kunci publik lainnya, harus ada cara yang mudah diterapkan untuk membangkitkan pasangan kunci enkripsi dan dekripsinya, sehingga setiap pemakai dapat membangkitkan sebuah pasangan tanpa perlu mempersoalkan kemampuan matematiknya [10].

Algoritma RSA memiliki besaran seperti berikut :

1. $p$ dan $q$ bilangan prima (rahasia)

2. $\mathrm{n}=\mathrm{p} . \mathrm{q}$ (tidak rahasia)

3. $m=(p-1)(q-1)$ (rahasia)

4. $\mathrm{e}=$ kunci enkripsi (tidak rahasia)

5. $\mathrm{d}=$ kunci dekripsi (rahasia)

6. $\mathrm{P}=$ plaintext (rahasia)

7. $\mathrm{C}=$ ciphertext (tidak rahasia)

Flowchart proses algoritma RSA dapat dilihat pada gambar berikut

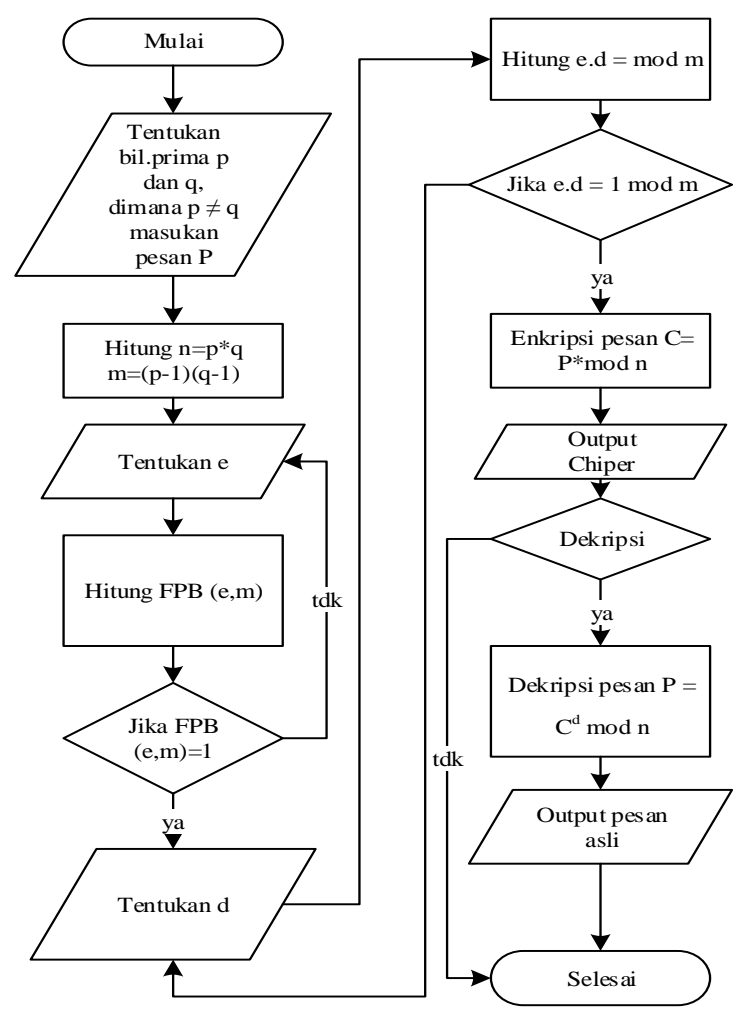

Gambar 1. Flowchart Proses Algoritma RSA [5].

\section{F. Keamanan RSA}

Keamanan algoritma RSA terletak pada tingkat kesulitan dalam memfaktorkan bilangan non prima menjadi bilangan faktor primanya, yang dalam hal ini $n=p \times q$. Sekali $n$ berhasil difaktorkan menjadi $p$ dan $q$, maka $m=(p-1)(q-1)$ dapat dihitung. Selanjutnta karena kunci enkripsi e diumumkan (tidak rahasia), maka kunci dekripsi d dapat dihitung dari persamaan $\mathrm{e}=1(\bmod \mathrm{m})$.

Penemu algoritma RSA menyatakan nilai $p$ dan q panjang lebih dari 100 digit. Dengan demikian hasil kali $\mathrm{n}=\mathrm{p} \times \mathrm{q}$ akan berukuran lebih dari 200 digit. Menurut Rivers dan kawan-kawan, usaha untuk mencari faktor bilangan 200 digit membutuhkan waktu komputasi selama 4 miliyar tahun [1].

\section{G. Website}

Website adalah suatu metode untuk menampilkan informasi di internet, baik berupa teks, gambar, suara maupun video yang interaktif dan mempunyai kelebihan untuk menghubungkan (link) satu dokumen dengan dokumen lainnya (hypertext) yang dapat diakses melalui sebuah browser [8]. 


\section{H. Hypertext Preprocessor PHP}

PHP adalah bahasa pemrograman yang digunakan secara luas untuk penanganan pembuatan dan pengembangan sebuah web dan bias digunakan pada HTML. PHP merupakan singkatan dari "PHP : Hypertext Preprocessor", dan merupakan bahasa yang disertakan dalam dokumen HTML, sekaligus bekerja di sisi server (server-side HTML-embedded scripting). Artinya sintaks dan perintah yang diberikan akan sepenuhnya dijalankan di server tetapi disertakan pada halaman HTML biasa, sehingga script-nya tak tampak disisi client. PHP dirancangan untuk dapat bekerja sama dengan database server dan dibuat sedemikian rupa sehingga pembuatan dokumen HTML yang dapat mengakses database menjadi begitu mudah. Tujuan dari bahasa scripting ini adalah untuk membuat aplikasi di mana aplikasi tersebut yang dibangun oleh PHP pada umumnya akan memberikan hasil pada web browser, tetapi prosesnya secara keseluruhan dijalankan di server [7].

\section{MySQL}

MySQL merupakan salah satu sistem database yang menggunakan structured query language (SQL) yakni bahasa yang berisi perintah perintah untuk memanipulasi database, mulai dari melakukan perintah select untuk menampilkan isi database, insert atau menambahkan isi kedalam database, delete atau menghapus isi database dan update atau mengedit database. MySQL pun dapat digunakan secara langsung dengan mengetikkan perintah atau syntaxnya melalui console. Dan bisa juga digunakan secara embeded SQL, artinya anda dapat menggunakan perintah SQL dengan menyisipkannya kedalam bahasa pemgrogaman tertentu misalnya PHP.

\section{J. Xampp}

XAMPP adalah perangkat lunak bebas, yang mendukung banyak sistem operasi, merupakan kompilasi dari beberapa program. Fungsinya adalah sebagai server yang berdiri sendiri (localhost) [7].

\section{METODE}

\section{Jenis Penelitian}

Penelitian ini menggunakan jenis penelitian kualitatif. Penelitian kualitatif adalah metode penelitian yang berlandaskan pada filsafat naturalistik, digunakan untuk meneliti pada kondisi objek yang alamiah. Penelitian kualitatif betujuan untuk menjelaskan fenomena dengan melalui pengumpulan data sedalam-dalamnya

\section{Tipe Penelitian}

Penelitian ini menggunakan tipe penelitian studi kasus. Penelitian studi kasus adalah penelitian yang memusatkan perhatian pada suatu kasus tertentu dengan menggunakan individu atau kelompok sebagai bahan studinya. Pada penelitian ini, penulis memfokuskan pada masalah penerima bantuan langsung masyarakat di lingkup Desa Beka, Kecamatan Marawola, Kabupaten Sigi.

\section{Jenis dan Sumber Data}

Jenis data pada penelitian ini adalah data primer dan data sekunder. Data primer yaitu data yang langsung dikumpulkan oleh peneliti dari sumber pertamanya. Sumber data pada penelitian ini diperoleh dari Desa Beka,Kecamatan Marawola, Kabupaten Sigi dan Dinas Sosial Kabupaten Sigi. Adapun yang menjadi sumber data primer dalam penelitian ini adalah Data Kriteria Masyarakat Miskin, Form validasi masyarakat rumah tangga miskin manual yang berasal dari Dinas Sosial Kabupaten Sigi, data masyarakat, yang bersumber dari Desa Beka Kecamatan Marawola, Kabupaten Sigi.

Data sekunder adalah data yang diperoleh dari pihak ketiga atau secara tidak langsung. Sumber data sekunder pada penelitian ini diperoleh dari bahan pustaka yang terkait dengan algoritma RSA dan Metode WP baik yang berasal dari jurnal, e-book, skripsi, dan artikel online. 


\section{HASIL DAN PEMBAHASAN}

\section{Analisa Sistem}

1.1. Diagam Konteks

Berikut adalah diagram konteks sistem.

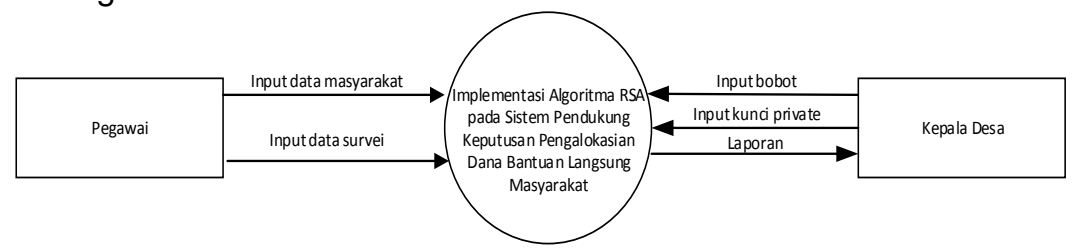

Gambar 1. Diagram Konteks implementasi algoritma RSA pada Sistem Pendukung Keputusan Pengalokasian Dana Bantuan Langsung Masyarakat

a. Pegawai

Pegawai melakukan penginputan data masyarakat dan data survei yang nantinya akan dijadikan sebagai rekomendasi pemberian bantuan dan diproses dalam sistem pendukung keputusan.

b. Kepala Desa

Kepala Desa melakukan penginputan bobot untuk setiap kiriteria dalam sistem pendukung keputusan dan mendeskripsikan data calon penerima bantuan langsung masyakat yang terenkripsi dengan memasukan kunci rahasia dan menerima data laporan masyarakat yang mendapat rekomendasi untuk menerima bantuan

c. Implementasi algoritma RSA pada Sistem pendukung keputusan pengalokasian dana bantuan langsung masyarakat dengan metode WP.

Sistem pendukung keputusan pengalokasian dana bantuan langsung masyarakat akan memberikan informasi kepada pegawai dan kepala desa mengenai masyarakat yang mendapatkan rekomendasi bantuan.

\subsection{Use Case Diagram}

Berikut adalah Use Case Diagram sistem, yang dapat dilihat pada gambar 2 Berikut.

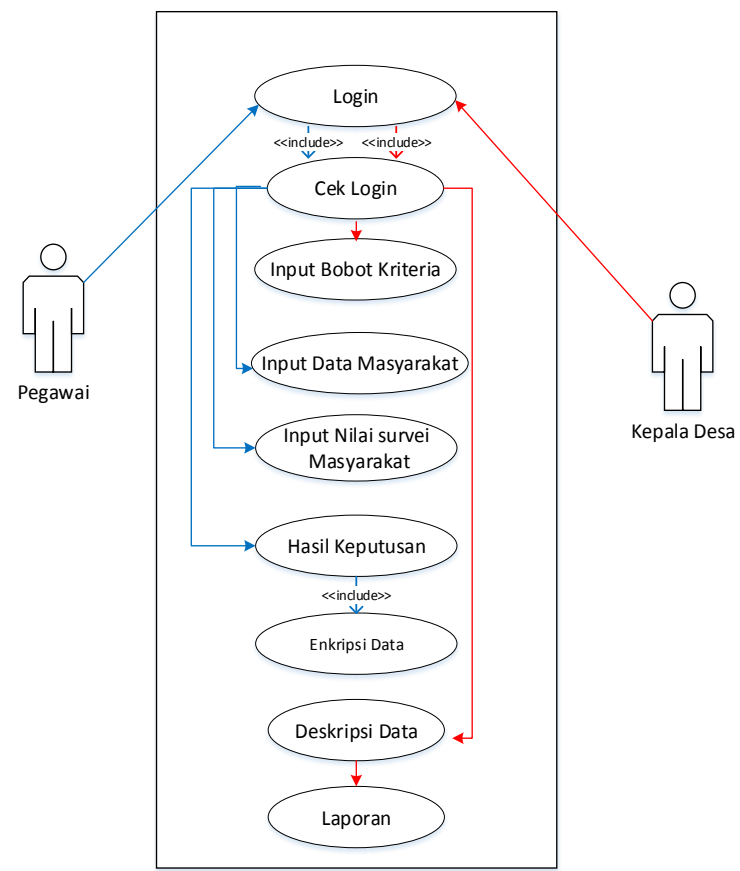

Gambar 2. Use Case diagram Sistem 
Keterangan gambar 2 dapat dilihat sebagai berikut:

a. Login

Pegawai ataupun kepala desa melakukan login sistem dengan memasukan nama pengguna dan kata sandi.

b. Input bobot kriteria

Pada tahap ini kepala desa memasukan data bobot pada setiap krtieria kedalam sistem.

c. Input data masyarakat

Tahap ini pegawai memasukan data lengkap masyarakat kedalam sistem.

d. Input nilai

Pegawai akan memasukkan penilaian masyarakat dan nilai akan diproses dalam perhitungan dengan metode Weighted Product untuk mendapatkan nilai akhir yang akan digunakan untuk menentukan masyarakat yang akan mendapatkan rekomendasi pemberian bantuan.

e. Hasil Keputusan

Pegawai akan mendapatkan hasil rekomendasi masyarakat penerima bantuan tetapi data hasil rekomendasi akan terenkripsi dengan algoritma RSA

f. Deskripsi

Kepala desa akan mendeskripsikan hasil rekomendasi masyarakat penerima bantuan yang terenkripsi

g. Laporan rekomendasi penerima bantuan

Kepala Desa dapat melihat hasil laporan data masyarakat yang mendapatkan rekomendasi.

\section{Implementasi Sistem}

1. Input data masyarakat

Form input data masyarakat dapat dilihat pada gambar 3 berikut:

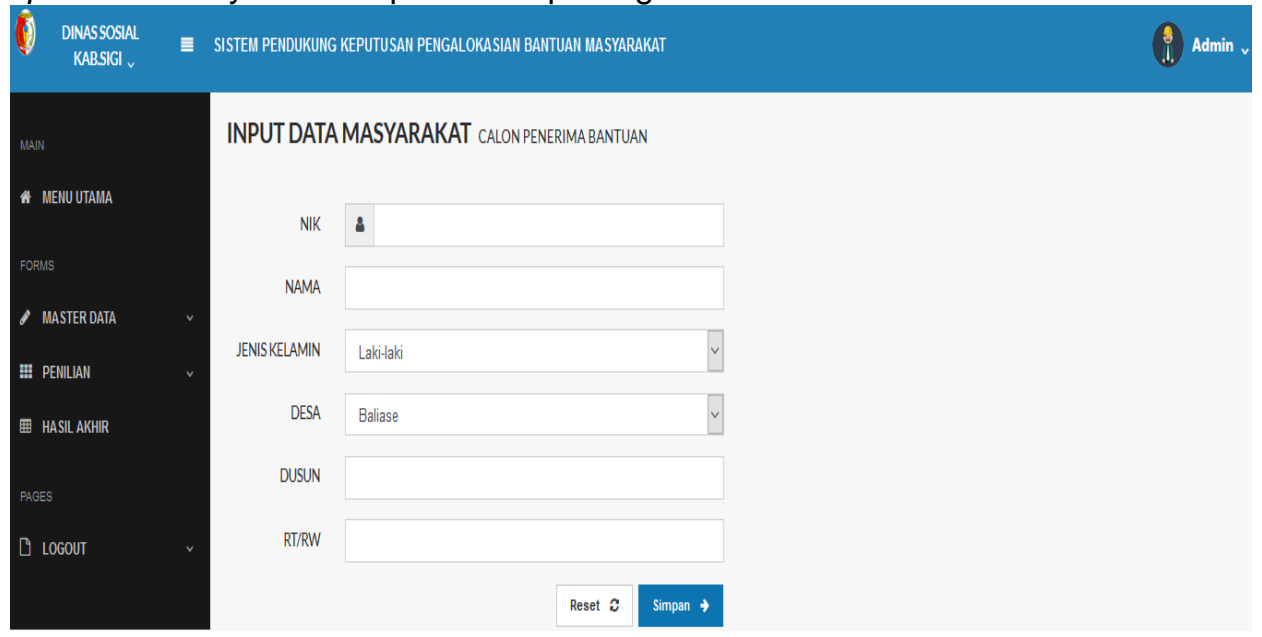

Gambar 3. Form input data masyarakat

Form ini digunakan untuk memasukkan data lengkap masyarakat dimana data yang dimasukkan yaitu NIK, nama masyarakat,desa, jenis kelamin, dusun, RT/RW seperti yang terlihat pada gambar 3.

2. Input data bobot kriteria

Form Input data bobot kriteria dapat dilihat pada gambar 4 sebagai Berikut: 


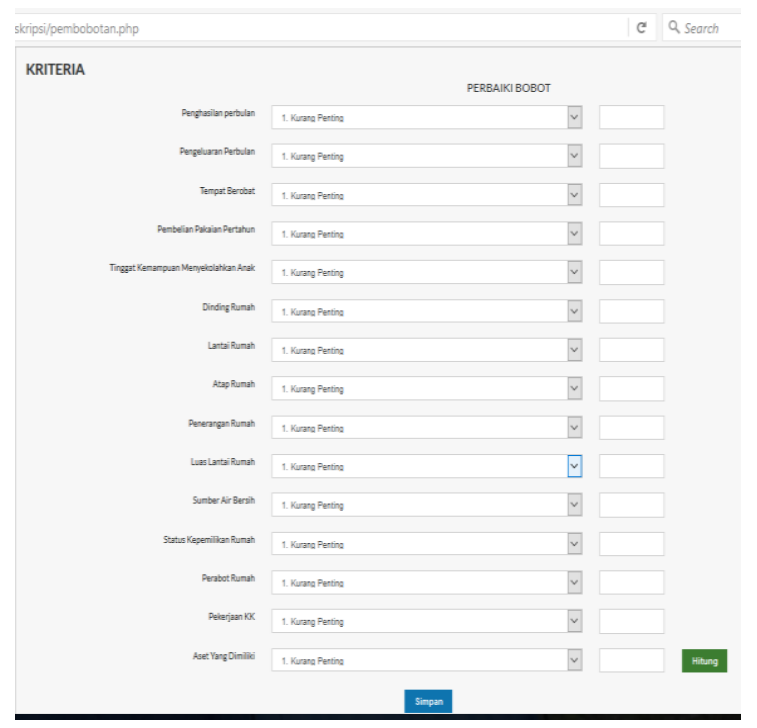

Gambar 4. Form input kriteria dan bobot.

Form ini digunakan untuk memasukkan data kriteria dan nilai bobot pada setiap kriteria. Data yang dimasukkan yaitu bobot kriteria, keterangan seperti yang terlihat pada gambar 4 .

\section{Input Survei RTM}

Form survei RTM dapat dilihat pada gambar 5 sebagai berukut

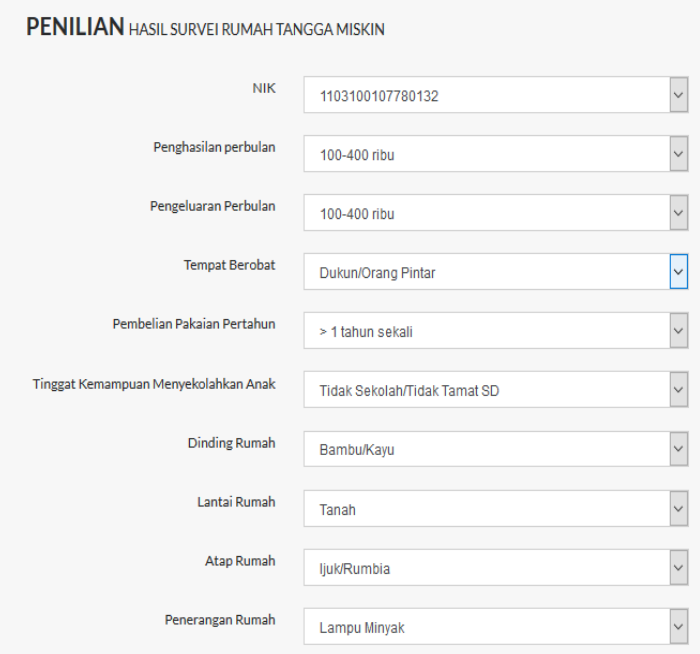

Gambar 5. Form survei RTM

Pada form ini digunakan untuk menginput nilai hasil survei yang akan diberikan kepada masyarakat untuk mendapatkan rekomendasi pemberian bantuan dimana data-data yang dimasukan $\mathrm{NIK}$, dan kriteria-kriteria pendukung seperti yang terlihat pada gambar 5.

4. Form data masyarakat

Form data masyarakat dapat dilihat pada gambar 6 sebagai berikut 


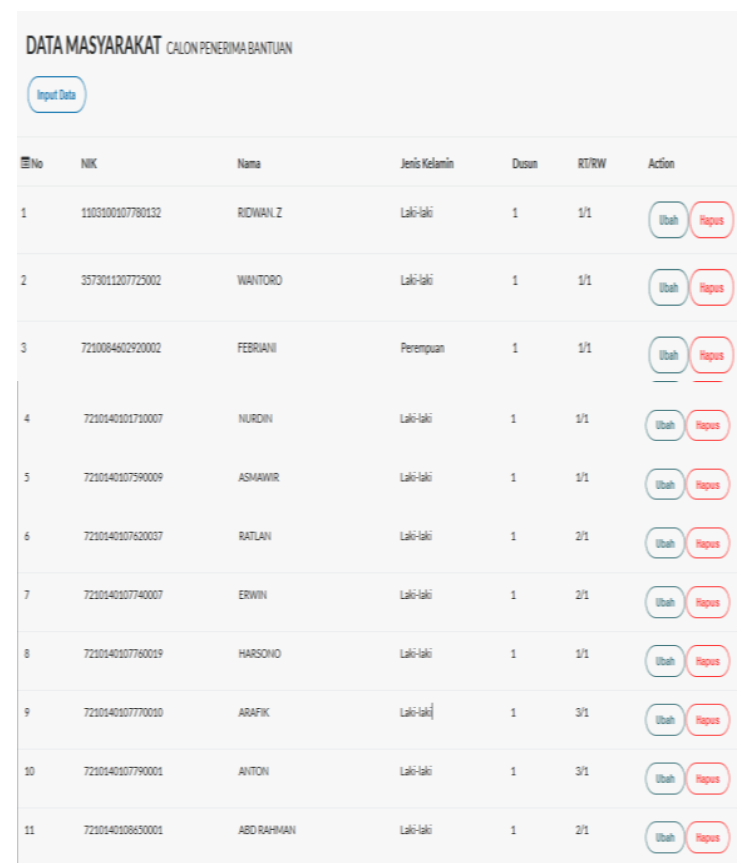

Gambar 6. Form data masyarakat

Form ini digunakan menampilkan semua data masyarakat yang telah dimasukkan kedalam sistem dan dapat melihat banyak jumlah masyarakat yang telah dimasukkan. Pada form ini juga dapat melihat data lengkap masyarakat dan dapat mengubah data masyarakat seperti yang terlihat pada gambar 6.

5. Form Proses Keputusan

Form Proses Keputusan dapat dilihat pada gambar 7 sebagai berikut :

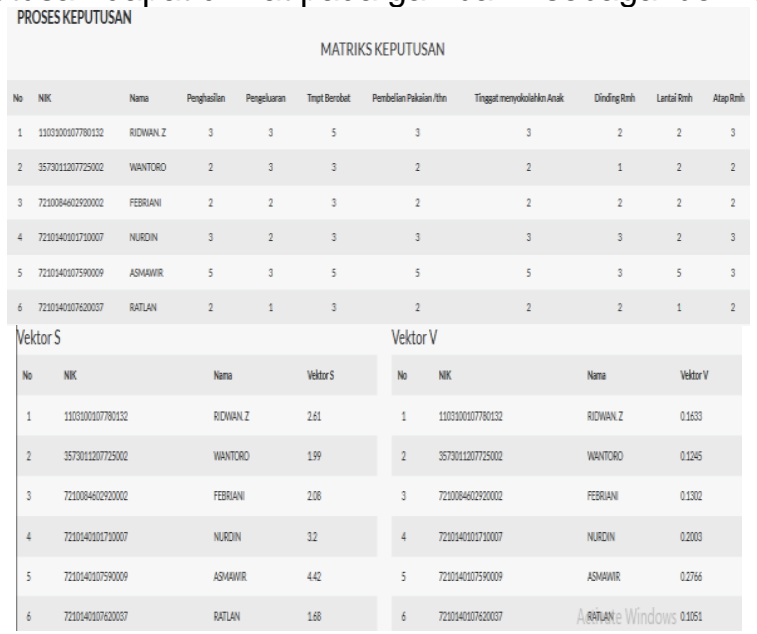

Gambar 7. Form Proses Keputusan

Form ini digunakan untuk menghitung nilai yang telah dimasukkan dengan menggunakan metode Weighted Product. Pada form ini juga terjadinya proses enkripsi menggunakan algoritma RSA, tetapi data hasil enkripsi tidak langsung ditampilkan pada form ini. seperti yang terlihat pada gambar 7.

6. Form rekomendasi penerima bantuan yang terenkripsi gambar 8

Berikut adalah Form rekomendasi penerima bantuan yang terenkripsi yang dapat dilihat pada 


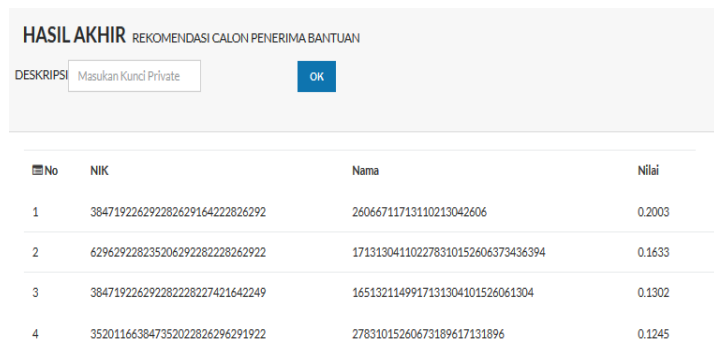

Gambar 8. Form rekomendasi penerima bantuan yang terenkripsi

Form ini digunakan untuk menampilkan data masyarakat yang layak untuk mendapatkan bantuan tetapi data yang ditampilkan masih terenkripsi, data dapat dideskripsi jika admin mengetahui kunci private deskripri dan data masyarakat yang terenkripsi dapat dicetak seperti yang terlihat pada gambar 8 .

7. Form cetak rekomendasi penerima bantuan yang terenkripsi

Form cetak rekomendasi penerima bantuan yang terenkripsi dapat dilihat pada gambar 9 .

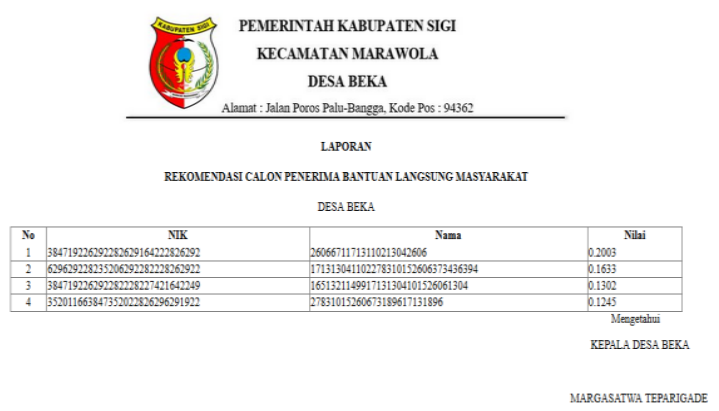

Gambar 9. Form cetak rekomendasi penerima bantuan yang terenkripsi

Form ini digunakan untuk menampilkan daftar nama masyarakat yang mendapatkan rekomendasi mendapatkan bantuan tetapi masih terenkripsi dan laporan ini dapat langsung dicetak untuk sebagai bukti laporan seperti terlihat pada gambar 9 .

8. Form cetak rekomendasi penerima bantuan yang terdeskripsi

Form cetak rekomendasi penerima bantuan yang terdeskripsi dapat dilihat pada gambar 10.

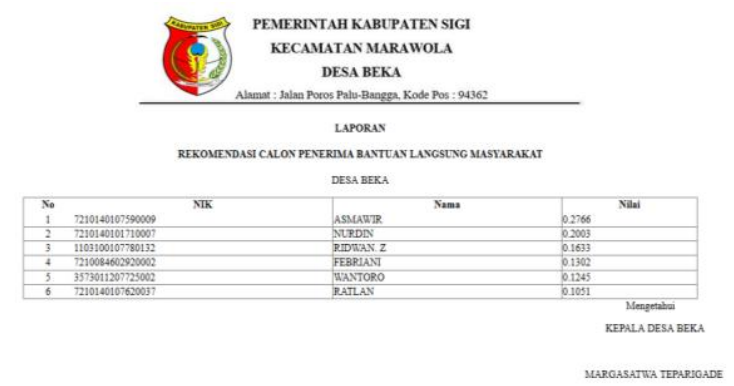

Gambar 10. Form cetak rekomendasi penerima bantuan yang terdeskripsi

Form ini digunakan untuk menampilkan daftar nama masyarakat yang mendapatkan rekomendasi mendapatkan bantuan yang telah terdeskripsi dan laporan ini dapat langsung dicetak untuk sebagai bukti laporan seperti terlihat pada gambar 10.

\section{Perhitungan Metode WP} berikut ini.

Nilai bobot kriteria yang diberikan dari Dinas Sosial Kabupaten Sigi dapat dilihat pada tabel 1 
Tabel 1. Tabel Nilai Bobot Kriteria

\begin{tabular}{|c|c|c|}
\hline Kriteria & Keterangan & Bobot \\
\hline $\mathrm{K} 1$ & $\begin{array}{c}\text { Penghasilan Per } \\
\text { Bulan }\end{array}$ & 4 \\
\hline K2 & $\begin{array}{c}\text { Pengeluaran Per } \\
\text { Bulan }\end{array}$ & 4 \\
\hline K3 & Tempat Berobat & 2 \\
\hline K4 & $\begin{array}{l}\text { Pembelian } \\
\text { Pakaian }\end{array}$ & 2 \\
\hline K5 & $\begin{array}{c}\text { Tingkat } \\
\text { Kemampuan } \\
\text { Menyekolahkan } \\
\text { Anak }\end{array}$ & 2 \\
\hline K6 & Dinding Rumah & 3 \\
\hline K7 & Lantai Rumah & 3 \\
\hline K8 & Atap Rumah & 3 \\
\hline K9 & $\begin{array}{l}\text { Penerangan } \\
\text { Rumah }\end{array}$ & 3 \\
\hline K10 & $\begin{array}{l}\text { Luas Lantai } \\
\text { Rumah }\end{array}$ & 3 \\
\hline K11 & $\begin{array}{l}\text { Sumber Air } \\
\text { Bersih }\end{array}$ & 3 \\
\hline K12 & $\begin{array}{c}\text { Status } \\
\text { Kepemilikan } \\
\text { Rumah }\end{array}$ & 3 \\
\hline K13 & Perabot Rumah & 3 \\
\hline K14 & Pekerjaan KK & 4 \\
\hline K15 & $\begin{array}{l}\text { Aset Yang } \\
\text { Dimiliki }\end{array}$ & 4 \\
\hline
\end{tabular}

(Sumber : Dinas Sosial Kabupaten Sigi)

1. Normalisasi Bobot Kriteria

Berikut adalah normaliasasi bobot kriteria dangan menggunakan persamaan (1) yang dapat dilihat dari W1,W2 sampai W15

$$
\begin{aligned}
& \mathrm{W} 1=\frac{4}{4+4+2+2+2+3+3+3+3+3}=0.087 \\
& \mathrm{~W} 2=\frac{4}{4+4+3+3+4+4} \\
& \mathrm{~W} 3=\frac{+2+2+2+3+3+3+3+3}{4+3+3+3+4+4}=0.087 \\
& \mathrm{~W} 4=\frac{2}{4+4+2+2+2+3+3+3+3+3}=0.043 \\
& \mathrm{~W} 5=\frac{+3+3+3+4+4}{4+4+2+2+2+3+3+3+3+3}=0.043 \\
& +3+3+3+4+4
\end{aligned}
$$




$$
\begin{aligned}
& \mathrm{W} 6=\frac{3}{4+4+2+2+2+3+3+3+3+3}=0.065 \\
& +3+3+3+4+4 \\
& \mathrm{~W} 7=\frac{3}{4+4+2+2+2+3+3+3+3+3}=0.065 \\
& +3+3+3+4+4 \\
& \mathrm{~W} 8=\frac{3}{4+4+2+2+2+3+3+3+3+3}=0.065 \\
& +3+3+3+4+4 \\
& \mathrm{~W} 9=\frac{3}{4+4+2+2+2+3+3+3+3+3}=0.065 \\
& \mathrm{~W} 10=\frac{3}{4+4+2+2+2+3+3+3+3+3}=0.065 \\
& +3+3+3+4+4 \\
& \mathrm{~W} 11=\frac{3}{4+4+2+2+2+3+3+3+3+3}=0.065 \\
& +3+3+3+4+4 \\
& \begin{array}{c}
\mathrm{W} 12=\frac{3}{4+4+2+2+2+3+3+3+3+3}=0.065 \\
+3+3+3+4+4
\end{array} \\
& \mathrm{~W} 13=\frac{3}{4+4+2+2+2+3+3+3+3+3}=0.065 \\
& +3+3+3+4+4 \\
& \mathrm{~W} 14=\frac{4}{4+4+2+2+2+3+3+3+3+3}=0.087 \\
& \mathrm{~W} 15=\frac{4}{4+4+2+2+2+3+3+3+3+3}=0.087
\end{aligned}
$$

Berikut adalah Hasil Normalisasi pembobotan kriteria yang dapat dilihat pada tabel 2 dan 3.

Tabel 2 Hasil Normalisasi Pembobotan kriteria

\begin{tabular}{|c|c|}
\hline Kriteria & Bobot Hasil Normalisasi \\
\hline K1 & 0.087 \\
\hline K2 & 0.087 \\
\hline K3 & 0.043 \\
\hline K4 & 0.043 \\
\hline K5 & 0.043 \\
\hline K6 & 0.065 \\
\hline K7 & 0.065 \\
\hline K8 & 0.065 \\
\hline K9 & 0.065 \\
\hline K10 & 0.065 \\
\hline K11 & 0.065 \\
\hline K12 & 0.065 \\
\hline K13 & 0.065 \\
\hline K14 & 0.087 \\
\hline
\end{tabular}




\begin{tabular}{|c|c|}
\hline $\mathrm{K} 15$ & 0.087 \\
\hline Total & 1 \\
\hline
\end{tabular}

Nilai inputan setiap kriteria pada masyarakat dapat dilihat pada tabel 3 dibawah ini.

Tabel 3. Nilai inputan setiap kriteria pada masyarakat

\begin{tabular}{|l|c|c|c|c|c|c|c|c|c|c|c|c|c|c|c|}
\hline & 1 & 2 & 3 & 3 & 5 & 6 & 7 & 8 & 9 & 10 & 11 & 12 & 13 & 14 & 15 \\
& & & & & & & & & & & & & & & \\
\hline $\begin{array}{l}\text { Ridwan } \\
\text { Z }\end{array}$ & 3 & 3 & 4 & 3 & 3 & 2 & 2 & 3 & 2 & 3 & 3 & 1 & 3 & 2 & 3 \\
\hline Wartono & 2 & 3 & 3 & 2 & 2 & 1 & 2 & 2 & 2 & 3 & 2 & 1 & 2 & 2 & 2 \\
\hline Febriani & 2 & 2 & 3 & 3 & 2 & 2 & 2 & 2 & 2 & 3 & 2 & 1 & 3 & 2 & 2 \\
\hline Nurdin & 3 & 2 & 3 & 3 & 3 & 3 & 2 & 3 & 2 & 4 & 4 & 4 & 3 & 4 & 3 \\
\hline Asnawir & 4 & 3 & 4 & 4 & 4 & 3 & 4 & 3 & 3 & 4 & 4 & 4 & 4 & 4 & 4 \\
\hline Ratlan & 2 & 1 & 3 & 2 & 2 & 2 & 1 & 2 & 2 & 3 & 2 & 1 & 1 & 1 & 2 \\
& & & & & & & & & & & & & & & \\
\hline
\end{tabular}

\section{Penentuan Vektor_S}

Berikut adalah penentuan nilai vektor $\mathrm{V}$ dengan menggunakan persamaan (2) yang dapat dilihat pada S1,S2 sampai S6.

$$
\begin{aligned}
& \text { Sl }=\left(3^{0.087}\right) \cdot\left(3^{0.087}\right) \cdot\left(4^{0.043}\right) \cdot\left(3^{0.043}\right) \cdot\left(3^{0.043}\right) \cdot\left(2^{0.065}\right) \cdot\left(2^{0.065}\right) \\
& \cdot\left(3^{0.065}\right) \cdot\left(2^{0.065}\right) \cdot\left(3^{0.065}\right) \cdot\left(3^{0.065}\right) \cdot\left(1^{0.065}\right) \cdot\left(3^{0.065}\right) \cdot\left(2^{0.087}\right) \\
& \left(3^{0.087}\right)=2.51 \\
& \mathrm{~S} 2=\left(2^{0.086}\right) \cdot\left(3^{0.086}\right) \cdot\left(3^{0.043}\right) \cdot\left(2^{0.043}\right) \cdot\left(2^{0.043}\right) \cdot\left(1^{0.065}\right) \cdot\left(2^{0.065}\right) \\
& \cdot\left(2^{0.065}\right) \cdot\left(2^{0.065}\right) \cdot\left(3^{0.065}\right) \cdot\left(2^{0.065}\right) \cdot\left(1^{0.065}\right) \cdot\left(2^{0.065}\right) \cdot\left(2^{0.086}\right) \\
& \left(2^{0.086}\right)=1.97 \\
& \text { S3 }=\left(2^{0.087}\right) \cdot\left(2^{0.087}\right) \cdot\left(3^{0.043}\right) \cdot\left(3^{0.043}\right) \cdot\left(2^{0.043}\right) \cdot\left(2^{0.065}\right) \cdot\left(2^{0.065}\right) \\
& \cdot\left(2^{0.065}\right) \cdot\left(2^{0.065}\right) \cdot\left(3^{0.065}\right) \cdot\left(2^{0.065}\right) \cdot\left(1^{0.065}\right) \cdot\left(3^{0.065}\right) \cdot\left(2^{0.087}\right) \\
& \left(2^{0.087}\right)=2,05 \\
& \mathrm{~S} 4=\left(3^{0.086}\right) \cdot\left(2^{0.086}\right) \cdot\left(3^{0.043}\right) \cdot\left(3^{0.043}\right) \cdot\left(3^{0.043}\right) \cdot\left(3^{0.065}\right) \cdot\left(2^{0.065}\right) \\
& \cdot\left(3^{0.065}\right) \cdot\left(2^{0.065}\right) \cdot\left(4^{0.065}\right) \cdot\left(4^{0.065}\right) \cdot\left(4^{0.065}\right) \cdot\left(3^{0.065}\right) \cdot\left(4^{0.016}\right) \\
& \left(3^{0.086}\right)=2.97 \\
& \mathrm{~S} 5=\left(4^{0.086}\right) \cdot\left(3^{0.086}\right) \cdot\left(4^{0.043}\right) \cdot\left(4^{0.043}\right) \cdot\left(4^{0.043}\right) \cdot\left(3^{0.065}\right) \cdot\left(4^{0.065}\right) \\
& \cdot\left(3^{0.065}\right) \cdot\left(3^{0.065}\right) \cdot\left(4^{0.065}\right) \cdot\left(4^{0.065}\right) \cdot\left(4^{0.065}\right) \cdot\left(4^{0.065}\right) \cdot\left(4^{0.086}\right) \\
& \left(4^{0.0866}\right)=3.67 \\
& \text { S6 }=\left(2^{0.086}\right) \cdot\left(1^{0.086}\right) \cdot\left(3^{0.043}\right) \cdot\left(2^{0.043}\right) \cdot\left(2^{0.043}\right) \cdot\left(2^{0.065}\right) \cdot\left(1^{0.065}\right) \\
& \cdot\left(2^{0.065}\right) \cdot\left(2^{0.065}\right) \cdot\left(2^{0.065}\right) \cdot\left(2^{0.065}\right) \cdot\left(1^{0.065}\right) \cdot\left(1^{0.065}\right) \cdot\left(1^{0.066}\right) \\
& \left(2^{0.086}\right)=1.61
\end{aligned}
$$

3. Menentukan Nilai vector_V

Dengan menggunakan persamaan (3) yang akan digunakan Menghitung Preferensi untuk perangkingan 


$$
\begin{aligned}
& V 1=\frac{2.51}{2.51+1.97+2,05+2.97+3.67+1.61}=0.1698 \\
& V 2=\frac{1.97}{2.51+1.97+2,05+2.97+3.67+1.61}=0.1333 \\
& V 3=\frac{2,05}{2.51+1.97+2,05+2.97+3.67+1.61}=0.1387 \\
& V 4=\frac{2.97}{2.51+1.97+2,05+2.97+3.67+1.61}=0.2009 \\
& V 5=\frac{3.67}{2.51+1.97+2,05+2.97+3.67+1.61}=0.2483 \\
& V 6=\frac{1.61}{2.51+1.97+2,05+2.97+3.67+1.61}=0.1089
\end{aligned}
$$

Jadi, bila direnking akan menghasilkan keputusan yang lebih direkomendasikan untuk memperoleh bantuan dapat dilihat pada tabel 4 .

\begin{tabular}{|c|c|c|c|}
\hline NO & NIK & NAMA & HASIL AKHIR \\
\hline 1 & 7210140107590009 & ASMAWIR & 0.2483 \\
\hline 2 & 7210140101710007 & NURDIN & 0.2009 \\
\hline 3 & 1103100107780132 & RIDWAN Z & 0.1698 \\
\hline 4 & 7210084602920002 & FEBRIANI & 0.1387 \\
\hline 5 & 3573011207725002 & WANTORO & 0.1333 \\
\hline 6 & 7210140107620037 & RATLAN & 0.1089 \\
\hline
\end{tabular}

Tabel 4. Hasil Perankingan Keputusan

Dari hasil perhitungan manual diatas data nilai masyarakat yang telah dimasukkan akan dihitung menggunakan metode Weigted Product (WP) untuk mendapatkan nilai akhir tertinggi masyarakat yang akan menjadi remkomendasi pemberian bantuan. Untuk dapat menentukan rekomendasi pemberian bantuan terdapat 6 tahapan yang dilakukan pada metode WP yaitu menentukan normalisasi Bobot, menghitung nilai hasil survei dengan bobot tiap kriteria sehingga menghasilakan Vektor_S dan menghitung nilai vektor_V yang diambil dari nilai vektor_S lalu di bagi untuk setiap atribut, dan tahap terakhir yaitu mengurutkan pilihan. Dari tahapan yang telah dilakukan maka nilai akhir tertinggi didapatkan oleh masyarakat yang mempunyai NIK 7210140107590009 dengan nilai 0.2483 dan nilai terendah didapatkan oleh masyarakat yang mempunyai NIK 7210140107620037 dengan nilai akhir 0.1089

\section{Kesimpulan dan Saran}

\section{Kesimpulan}

Berdasarkan hasil pengujian dan analisis sistem pendukung keputusan pengalokasian dana bantuan langsung masyarakat menggunakan metode Weighted Product (WP) yang diimplementasikan dengan algoritma RSA dapat diambil kesimpulan:

1. Proses perhitungan dengan metode WP pada sistem pendukung keputusan ini dapat dilakukan dengan memasukkan nilai bobot kriteria dan penilaian yang diberikan kepada masyarakat

2. Terdapat 3 langkah yang harus diperhatikan dalam penyelesaian menggunakan metode WP yaitu melakukan normalisasi bobot kriteria, melakukan perhitungan pemangkatan vektor $\mathbf{S}$ terhadap bobot kriteria, melakukan proses alternatif keputusan vektor $\mathrm{S}$ sehingga menghasilkan nilai vektor $\mathrm{V}$ dan langkah terakhir yaitu mengurutkan pilihan.

3. Terdapat 3 langkah yang harus dilakukan dalam penyelesaian menggunakan metode algoritma RSA yaitu Pembuatan Kunci private dan public, melakukuan enkripsi terhadap data dan yang terakhir yaitu mendeskripsikan data yang terenkripsi

4. Sistem pendukung keputusan ini dibangun menggunakan bahasa pemrograman Preprocessor HyperText (PHP) berbasis website dan sistem ini dapat membantu pegawai balai Desa Beka dalam menentukan masyarakat yang akanmendapatkan rekomendasi mendapatkan bantuan dan sistem dapat mengurutkan data masyarakat yang mendapatkan rekomendasi. 
5. Tingkat keakurasi perhitungan manual metode WP dengan sistem yang dibangun $98 \%$ hasilnya adalah sama

\section{Saran}

Pada penelitian ini masih terdapat beberapa kekurangan, sehingga diharapkan pada penelitian selanjutnya diperlukan perbaikan untuk pengembangan lebih lanjut, diantaranya:

1. Untuk setiap laporan tidak hanya dapat dicetak langsung tetapi juga dapat dikonversi kebentuk file dokumen Microsoft Excel atau Microsoft Word.

2. Perlu ditambahkan suatu metode atau algoritma yang dapat membandingkan nilai akhir apabila terjadi kesamaan nilai akhir agar dapat menentukan urutan peringkat terbaik.

\section{Daftar Pustaka}

[1] Agustina, A.N, Aryanti, \& Nasron. 2017. Pengamanan Dokument Menggunakan Metode Rsa (Rivest Shamir Adleman)Berbasis Web, Politeknik Negeri Sriwijaya. Palembang

[2] Faridl, M. 2015. Fitur Dahsyat Sublime Text 3. Penerbit : STIKOM Surabaya.

[3] Hendini, A , 2016 Pemodelan UmI Sistem Informasi Monitoring Penjualan Dan Stok Barang (Studi Kasus: Distro Zhezha Pontianak), No. 2 , vol. 4, Program Studi Manajemen Informatika AMIK BSI Pontianak.

[4] Iswandi, E. 2015. Sistem Penunjang Keputusan Untuk Menentukan Penerimaan Dana Santunan Sosial Anak Nagari Dan Penyalurannya Bagi Mahasiswa Dan Pelajar Kurang Mampu Di Kenagarian Barung - Barung Balantai Timur No.2 Vol.3, STMIK Jayanusa,Padang

[5] Muzakir.A dan Rahman.M, 2017. Ujicoba sistem keamanan informasi dengan algoritma Kriptografi RSA dan RSA-Crt pada sistem E-Memo berbasis mobile. Jurnal SIMETRIS, No.2,Vol.18 Program Studi Teknik Informatika,Fakultas Ilmu Komputer,Universitas Bina

[6] Pabokory, F.N, Astuti.I.F \& Kridalaksana.A.H. 2015. Implementasi Kriptografi Pengamanan Data Pada Pesan Teks, Isi File Dokumen, Dan File Dokumen Menggunakan Algoritma Advanced Encryption Standard, No. 1, Vol. 10. Program Studi IImu Komputer, FMIPA, Universitas Mulawarman.

[7] Palit,R.V , Rindengan, Y.D.Y, \&. Lumenta, A.S.M, 2015 Rancangan Sistem Informasi Keuangan Gereja Berbasis Web Di Jemaat GMIM Bukit Moria Malalayang, No.7 ,vol.4, Jurusan Teknik Elektro-FT. UNSRAT, Manado

[8] Ridwan.M, Arifin.Z, \& Yulianto. 2016. Rancang Bangun E-Voting Dengan Menggunakan Keamanan Algoritma Rivest Shamir Adleman (Rsa) Berbasis Web (Studi Kasus : Pemilihan Ketua Bem Fmipa). No. 2

[9] Ronando.E. \& Indasyah.E. 2017. Sistem Pengambil Keputusan Untuk Penentuan Penerima Bantuan Langsung Masyarakat Pnpm Mandiri Menggunakan Simple Additive Weighting (Studi Kasus Kecamatan Ngadirojo Kabupaten Pacitan), No 2, Volume 1. Teknik Informatika, Universitas 17 Agustus 1945 Surabaya.

[10] Setiaji, B. 2015. Analisis Dan Implementasi Algoritma Kriptografi Kunci Publik Rsa Dan Luc Untuk Penyandian Data. Jurnal IImiah DASI, No. 3, Vol. 16, hlm 27 - 36. Teknik Informatika STMIK AMIKOM Yogyakarta.

[11] Syafitri, N.A, Sutardi, Dewi.A.P. 2015. Penerapan Metode Weighted Product Dalam Sistem Pendukung Keputusan Pemilihan Laptop Berbasis Web. No.1 Vol.2, Jurusan Teknik Informatika, Fakultas Teknik, Universitas Halu Oleo, Kendari. 